\title{
Analisis Shear Strain dan Kerusakan Bangunan Akibat Gempa Bumi di Kecamatan Gading Cempaka dan Ratu Agung Kota Bengkulu
}

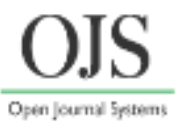

\author{
Kurnia Lestari $^{1 *}$, Muchammad Farid ${ }^{2}$, Afrizal Mayub ${ }^{1}$ \\ ${ }^{1}$ Pascasarjana Pendidikan IPA, FKIP Universitas Bengkulu \\ ${ }^{2}$ Jurusan Fisika, FMIPA Universitas Bengkulu \\ "Email: lestarikurnia302@gmail.com
}

\begin{abstract}
[The Analysis of Shear Strain and Building Damage due to Earthquake at Gading Cempaka and Ratu Agung District in Bengkulu City]. The aims of this research are to: (1) determine and mapping the distribution of shear strain values, (2) correlate between shear strains with building damage Gading Cempaka and Ratu Agung caused by earthwuake at sub district in Bengkulu city. Microtremor data were taken at 108 observation points then analyzed using HVSR method to obtain amplification factor and dominant frequency values..The result showed that shear strain value of Gading Cempaka and Ratu Agung sub district in Bengkulu city are relatively heterogeneous although in the same geological formation type. The earthquake in 2007 is estimated to be $3.38 \%$ potential to deform the land surface in the form of fractures and settlements and 96, 62\% potentially experience shocks due to waves and vibrations due to earthquake. The earthquake of 2000 estimated that almost the entire area of Gading Cempaka and Ratu Agung has the potential to experience shocks due to waves and vibrations due to earthquake that is equal to $97 \%$ while potentially liquefaction (ambles) occurs by $3 \%$. The correlation between shear strain with the damage of buildings due to earthquake shows the relationship is directly proportional to the function $y=15267 x+26.219$ with the coefficient of resgression of $R^{2}=0.671$.
\end{abstract}

Keywords: Earthquake; HVSR method; microtremor; shear strain.

\begin{abstract}
ABSTRAK
Penelitian ini bertujan untuk: (1) menentukan dan memetakan sebaran nilai shear strain , (2) mengkorelasikan antara shear strain dengan kerusakan bangunan di Kec. Gading Cempaka dan Ratu Agung Kota Bengkulu. Data mikrotremor diambil di 108 titik pengamatan kemudian dianalisis menggunakan metode HVSR untuk memperoleh nilai faktor amplifikasi dan nilai frekuensi dominan. Hasil penelitian menunjukan bahwa Nilai shear strain Kec. Gading Cempaka dan Ratu Agung Kota Bengkulu relatif heterogen meskipun pada jenis formasi geologi yang sama. Gempa bumi tahun 2007 diestimasikan 3,38 \% berpotensi mengalami deformasi permukaan tanah berupa rekahan dan settlement dan 96, $62 \%$ berpotensi mengalami goncangan akibat gelombang dan getaran akibat gempa bumi. Gempa bumi tahun 2000 diestimasikan hampir keseluruhan daerah Gading Cempaka dan Ratu Agung berpotensi mengalami goncangan akibat gelombang dan getaran akibat gempa bumi yaitu sebesar $97 \%$ sedangkan yang berpotensi terjadi liquefaction (ambles) sebesar $3 \%$. Korelasi antara shear strain dengan kerusakan bangunan akibat gempa bumi menunjukkan hubungan berbanding lurus dengan fungsi $y=15267 x+26,219$ dengan koefisien resgresi sebesar $R^{2}=0.671$.
\end{abstract}

Kata Kunci : Gempa bumi; metode HVSR; mikrotremor; shear strain.

\section{PENDAHULUAN}

Shear adalah tegangan dan strain adalah regangan. Shear strain adalah kemampuan material lapisan tanah untuk saling meregang atau bergeser saat terjadi gempa bumi (Nakamura, 2000).

Secara geografis Provinsi Bengkulu terletak pada posisi $101^{\circ} 1^{\prime}-103^{\circ} 46^{\prime} \mathrm{BT}$ dan $2^{\circ} 16^{\prime}-5^{\circ} 13^{\prime} \mathrm{LS}$, membujur sejajar dengan 
Bukit Barisan dan berhadapan langsung dengan Samudra Hindia dengan panjang garis pantai $\pm 525 \mathrm{~km}$ dan luas teritorial 48.075 $\mathrm{Km}^{2}$, memanjang dari perbatasan Provinsi Sumatera Barat sampai ke perbatasan Provinsi Lampung (BPS, 2008). Posisi Provinsi Bengkulu diapit oleh zona subduksi (penunjaman) antara lempeng HindiaAustralia dan Euro-Asia di sebelah barat dan zona Sesar Sumatera di sebelah timur (Lubis dan Hasima, 2012) yang mengakibatkan Kota Bengkulu merupakan daerah yang sangat rawan terhadap bencana gempa bumi (Farid, 2013).

Pada tanggal 4 Juni 2000, telah terjadi gempa bumi dengan kekuatan $\mathrm{Mw}=7,9$ yang menyebabkan lebih dari 90 orang meninggal dunia, 18.928 tempat tinggal rusak ringan dan 10.460 rusak berat, serta kerusakakn sarana dan prasarana seperti instalasi air bersih, jalan, jembatan, saluran drainase, perkantoran pemerintah, sekolah, pasar dan rumah sakit Gempa bumi pada tanggal 12 September 2007, pukul 18:10 WIB dengan letak pusat gempa $4,44^{\circ}$ LS $101,37^{\circ}$ BT dengan kedalaman 34 $\mathrm{km}$ dan $\mathrm{mw}=8,5$ yang menyebabkan 3 orang meninggal dunia, lebih dari 1.400 rumah rusak ringan dan 2000 rusak berat (Harlianto, 2013).

Kecamatan (Kec.) Gading Cempaka dan Kec. Ratu Agung merupakan salah satu Kec. yang ada di Kota Bengkulu yang mempunyai tingkat resiko tinggi terhadap fenomena alam bencana gempa bumi. Berdasarkan pengamatan di lapangan, khususnya untuk kejadian gempa tahun 2000 dan tahun 2007 diketahui bahwa di daerah Kecamatan Gading Cempaka dan Kec. Ratu Agung merupakan daerah yang mengalami kerusakan bangunan yang parah. Secara garis besar tingkat kerusakan akibat gempa bergantung dari kekuatan dan kualitas bangunan, kondisi geologi, geotektonik lokasi bangunan, percepatan getaran tanah dan tingkat kerentanan seismik di suatu lokasi gempa bumi. (Edwiza, 2008).

Berdasarkan fakta - fakta tersebut menunjukkan bahwa potensi terjadinya gempa bumi disekitar Kota Bengkulu khususnya Kec. Gading Cempaka dan Kec. Ratu Agung di masa yang akan datang masih sangat tinggi. Hal ini tentu sangat membahayakan bagi masyarakat, apabila tidak disertai dengan peningkatan kesiapsiagaan masyarakat dan pemerintah setempat dalam mengantisipasi potensi bencana tersebut.

Banyaknya pusat gempa bumi di wilayah Kota Bengkulu, dapat diketahui dengan menganalisa indikator - indikator yang berkaitan dengan kejadian gempa bumi. Indikator umum yang penting untuk diketahui adalah Indeks Kerentanan Seismik (IKS), Peak Ground Acceleration (PGA) dan Shear Strain. Indeks kerentanan seismik didefinisikan sebagai indeks yang menggambarkan tingkat kerentanan lapisan tanah permukaan terhadap deformasi saat terjadi gempa bumi (Nakamura, 2000). Peak ground acceleration merupakan getaran tanah maksimum yang pernah terjadi 4di suatu tempat dalam kurun waktu tertentu (Campbell dan Bozorgnia, 2006).

\section{Gelombang gempa}

Pelepasan energi tegangan mendadak oleh rekahan pada tepian lempeng tektonik merupakan penyebab utama dari aktifitas gempa, yang menyebabkan menjalarnya getaran pada bagian bumi dalam bentuk gelombang. Gelombang gempa merupakan gangguan elastis (elastic disturbances) dan ketika batas elastisitas dilampaui batuan yang dilaluinya akan kembali kebentuk semula. Gelombang gempa terdiri atas gelombang badan (body waves) dan gelombang permukaan (surface waves) (Waluyo, 2002). Gelombang teridiri dari 1) gelombang Badan (Body Wave), gelombang badan menjalar menjauhi fokus dan mampu merambat ke segala arah. Jenis gelombang badan yang pertama adalah gelombang kompresi (compressional waves). Gelombang kompresi merupakan gelombang pertama yang mencapai stasiun pencatat gempa maka dinamakan juga gelombang $\mathrm{P}$ (primary wave) 2) Gelombang Permukaan (Surface Wave), gelombang permukaan merambat di permukaan bumi sebagai getaran horizontal dan vertikal. Kecepatannya lebih rendah dari gelombang $\mathrm{P}$ dan $\mathrm{S}$, oleh karena itu terekam pada stasiun gempa terakhir kali. Gelombang permukaan terdiri dari dua jenis yaitu gelombang Love dan gelombang Rayliegh.

\section{Shear strain}

Sebuah medium atau benda padat berada dalam keadaaan setimbang dipengaruhi gaya-gaya yang berusaha menarik, menggeser, 
atau menekannya maka bentuk benda tersebut akan berubah (terdeformasi). Jika benda kembali ke bentuknya semula bila gaya-gaya dihilangkan maka benda dikatakan elastik. Hubungan antara gaya dan deformasinya dapat dijelaskan dengan menggunakan konsep tegangan (stress), regangan (strain), hukum Hooke dan konstanta elastiknya. Shear strain dihitung berdasarkan pengukuran mikrotremor di setiap lokasi yang diteliti. Data mikrotremor hasil pengukuran diolah menggunakan Geopsy dengan metode HVSR. Nakamura (2000) melakukan pendekatan secara empirik untuk menghitung shear strain dan hasilnya ditunjukkan pada persamaan 1 (. H. Huang and Y. Tsen yaitu :

$$
\gamma=K g \times \alpha\left(10^{-6}\right)
$$

Keterangan : $\gamma$ adalah shear strain, $K_{g}$ adalah Indeks kerentanan seismik, dan $\alpha$ adalah Percepatan tanah maksimum (gal). Lapisan tanah permukaan akan bersifat plastis pada nilai $\gamma=1.000 \times 10^{-6}$, sedangkan pada $\gamma$ $>1.000 \times 10^{-6}$ lapisan tanah dapayt mengalami deformasi (Isihara, 1982). Gempa bumi merusak biasanya terjadi bilamana batas shear strain terlampaui, sehingga terjadi deformasi lapisan tanah. Hubungan antara shear strain dengan sifat dinamik tanah dapat dilihat pada Tabel 1.

Tabel 1. Hubungan nilai shear strain dengan sifat dinamik tanah (Isihara, 1982).

\begin{tabular}{|l|l|l|l|}
\hline $\begin{array}{l}\text { Size of } \\
\text { strain }\end{array}$ & $10^{-6} 10^{-5}$ & $10^{-4} 10^{-3}$ & $\begin{array}{l}10^{-2} \\
10^{-1}\end{array}$ \\
\hline Phenomena & $\begin{array}{l}\text { Wave, } \\
\text { Vibration }\end{array}$ & $\begin{array}{l}\text { Crack, } \\
\text { Settleme } \\
\text { nt }\end{array}$ & $\begin{array}{l}\text { Landslide, } \\
\text { Soil } \\
\text { Compaction, } \\
\text { Liquefaction }\end{array}$ \\
\hline $\begin{array}{l}\text { Dynamic } \\
\text { Properties }\end{array}$ & Elasticity & $\begin{array}{l}\text { Elasto- } \\
\text { Plasticity }\end{array}$ & $\begin{array}{l}\text { Repeat- } \\
\text { effect, Speed } \\
\text { effact of } \\
\text { loading }\end{array}$ \\
\hline
\end{tabular}

\section{METODE PENELITIAN}

\section{Jenis Penelitian}

Jenis penelitian ini merupakan gabungan dari penelitian eksperimen untuk menganalisis shear strain dan kerusakan bangunan akibat gempa bumi dengan menggunakan data mikroseismik
Penelitian ini telah dilakukan pada bulan Januari - Maret 2018. Pengambilan data primer berupa pengukuran mikrotremor secara langsung di wilayah Kec. Gading Cempaka dan Ratu Agung Kota Bengkulu dengan 118 titik pengukuran Berikut gambar sebaran stasiun seismik pada Gambar 1 di bawah ini:

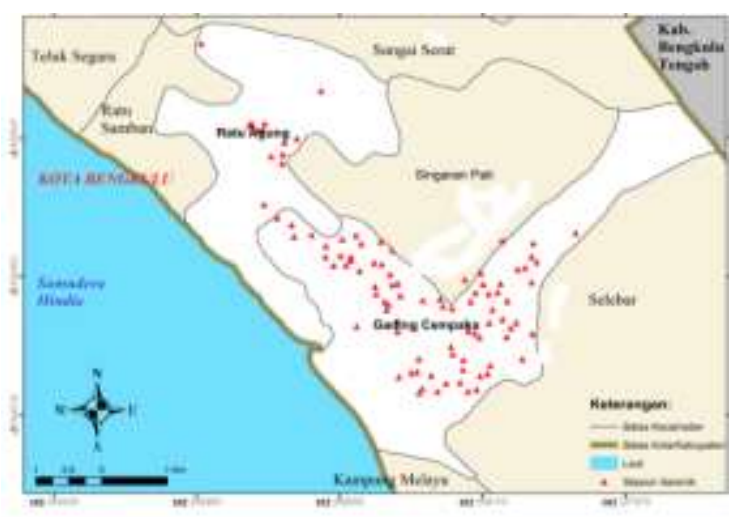

Gambar 1. Peta Sebaran Stasiun seismik

\section{Instrumen Penelitian}

Alat yang digunakan dalam penelitian sains adalah satu set seismometer portable short period yang terdiri dari seismometer PASI Mod Gemini 2 Sn-1405, Global Positioning System (GPS), Kabel Kompas, Laptop, Lembar check list mikrotremor.

\section{Tahap Pengambilan Data}

Pengambilan data akan dilakukan pada Januari 2018. Pengambilan data pada setiap titik pengukuran untuk mendapatkan posisi geografis terbagi atas dua tahap yaitu penentuan titik-titik pengambilan data dan pelaksanaan akuisisi data. Penentuan titik didasarkan pada real wilayah yang mengalami kerusakan. Pengambilan data dilakukan dengan alat Seismometer Portable short period tipe TDL 303S, data yang diambil untuk 3 komponen yaitu NS, EW dan komponen vertikal (up-down) dengan 118 titik pengkuran. Penentuan titik pengukuran dilakukan secara acak sesuai dengan bangunan yang rusak ketika terjadi gempa bumi tahun 2000 dan 2007. Jarak titik satu dengan titik lainnya diperirakan 100 - 300 m. Pada setiap satu titik pengukuran dilakukan pengambilan data selama 20 menit.

\section{Waktu dan Tempat Penelitian}




\section{Analisa Data}

Dari data yang diperoleh maka akan dilakukan analisis : Nilai frekuensi dominan $f_{o}$, amplifikasi $A_{O}$, indeks kerentanan $K g$, peak ground acceleration (PGA) $\alpha$, shear strain $\gamma$, di Kec. Gading Cempaka Kota Bengkulu. Selanjutnya dihubungkan dengan kerusakan bangunan. Apabila nilai shear strain-nya besar dan lunak maka didaerah tersebut kemungkinan kerusakannya akan semakin parah dan apabila nilai shear strain-nya kecil dan sedimennya tipis maka kemungkinan kerusakannya akan semakin kecil.

\section{HASIL DAN PEMBAHASAN}

Distribusi Nilai shear strain di Kec. Gading Cempaka dan Ratu Agung Kota Bengkulu

Distribusi nilai shear strain Kec. Gading Cempaka dan Ratu Agung Kota Bengkulu bervariasi meskipun pada jenis formasi geologi yang sama. Secara umum nilai shear strain di bagi kedalam tiga katagori yaitu $1 \times 10^{-4}, 1 \times 10^{-3}$ dan $1 \times 10^{-2}$. Peta sebaran nilai shear strain pada tahun 2000 dan $20071 \times 10^{-4}$ ditandai dengan warna kuning, 1 x $10^{-3}$ warna oren dan $1 \times 10^{-2}$ warna merah. Gempa bumi tahun 2007 diestimasikan 3,38 \% berpotensi mengalami deformasi permukaan tanah berupa rekahan dan settlement dan 96, $62 \%$ berpotensi mengalami goncangan akibat gelombang dan getaran akibat gempa bumi. Gempa bumi tahun 2000 diestimasikan hampir keseluruhan daerah Gading Cempaka dan Ratu Agung berpotensi mengalami goncangan akibat gelombang dan getaran akibat gempa bumi yaitu sebesar $97 \%$ sedangakan yang berpotensi terjadi liquefaction (ambles) sebesar $3 \%$. Secara detaeil distribusi nilai shear strain di Kec. Gading Cempaka dan Ratu Agung Kota Bengkulu ditunjukan pada Gambar 2 gempa tahun 2000 dan Gambar 3 gempa tahun 2007.

Kerusakan bangunan akibat gempa bumi berbanding lurus dengan nilai shear strain yang tinggi. Huang dan Tseng (2002) yang menyatakan bahwa daerah Yuan Lin yang mengalami kerusakan parah ternyata terletak pada zona shear strain tinggi berdasarkan data mikrotremor. Formulasi ini terjawab dengan hubungan antara shear strain dengan kerusakan bangunan akibat gempa bumi seperti ditunjukkan pada Gambar 4.

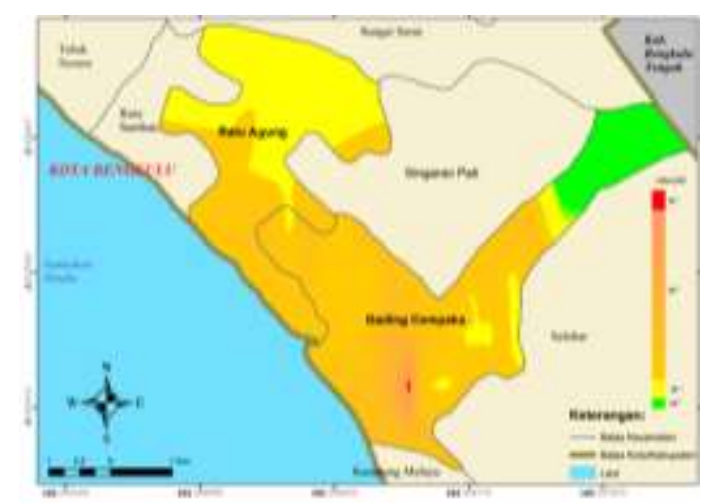

Gambar 2. Peta Sebaran Shear Strain pada tahun 2000

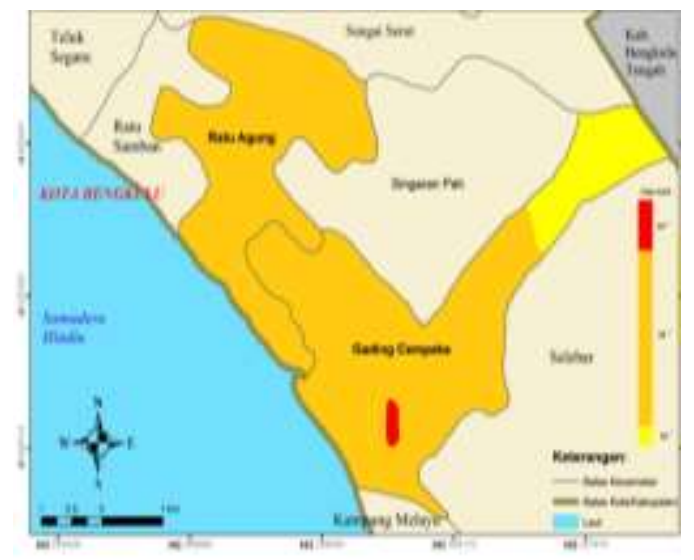

Gambar 3. Peta Sebaran Shear Strain pada tahun 2007

Grafik hubungan Kerusakan Bangunan dengan nilai shear strain

Gambar 4 menunjukkan hubungan berbanding lurus antara shear strain dengan kerusakan bangunan, semakin tinggi nilai shear strain maka tingkat kerusakan juga akan semakin tinggi. Hubungan shear strain dengan kerukan bangunan dengan fungsi $: y=$ $15267 x+26,219$ Dimana $Y$ adalah shear strain dan $X$ adalah indeks kerusakan Dengan koefisien resgresi sebesar $R^{2}=0.671$, berarti fungsi ini dapat dipercaya untuk tingkat kebenaran yang cukup meyakinkan. Suatu data memiliki hubungan jika memiliki nilai 0,6 $\geq \boldsymbol{R}^{2} \leq \mathbf{1}$ (Anastasi dan Urbina, 1997). 


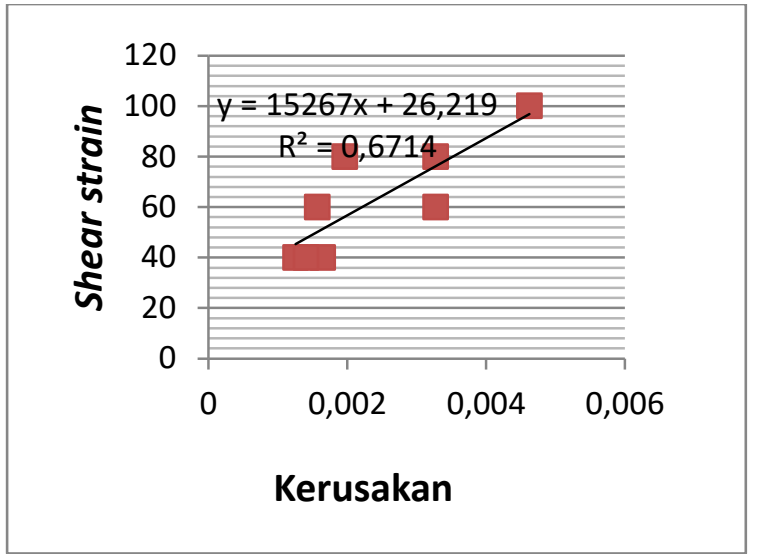

Gambar 4. Grafik Hubungan Shear strain dengan Kerusakan Bangunan

\section{KESIMPULAN}

Nilai shear strain di Kota Bengkulu relatif heterogen meskipun pada jenis formasi geologi yang sama. Gempa bumi tahun 2000 diestimasikan hampir keseluruhan daerah Gading Cempaka dan Ratu Agung berpotensi mengalami goncangan akibat gelombang dan getaran akibat gempa bumi yaitu sebesar $97 \%$ sedangakan yang berpotensi terjadi liquefaction (ambles) sebesar $3 \%$. Gempa bumi tahun 2007 diestimasikan 3,38 \% dari luasan Kec. Gading Cempaka dan Ratu Agung Kota Bengkulu berpotensi mengalami deformasi permukaan tanah berupa rekahan dan settlement dan 96, $62 \%$ berpotensi mengalami goncangan akibat gelombang dan getaran akibat gempa bumi. Korelasi antara shear strain dengan kerusakan bangunan menunjukkan hubungan berbanding lurus antara shear strain dengan kerusakan bangunan dengan fungsi $y=15267 x+$ 26,219 dan koefisien resgresi $R^{2}=0.671$.

\section{DAFTAR PUSTAKA}

Anastasi, A. dan Urbina, S. 1997. Psychological Testing Seventh Edition. United State: Pearson Prentice Hall.

Campbell, K.W., and Bozorgnia, Y. 2006. Campbell-Bozorgnia NGA Empirical Ground Motion Model for theAverage Horizontal Component of PGA,PGV, $P G D$ and $S A$ at Selected SpectralPeriods Ranging from 0.0110.0 Seconds(Version 1.1). California:
Pacific Earthquake Engineering

Research Center, College of Engineering, University of California, Berkeley.

BPS. 2008, Posisi Geografis Provinsi Bengkulu.

Edwiza, D. 2008. Pemetaan Percepatan Tanah Maksimum dan Intensitas Seismik Kota Padang Panjang Menggunakan Metode Kanai. Teknik A No. 29 Vol.2: UNPAD.

Farid, M. 2013. Pemetaan Percepatan Getaran Tanah Maksimum dan Kerentanan Seismik Akibat Gempa bumi untuk Mendukung Rencana Tata Ruang dan Wilayah (RTRW) Kota Bengkulu. Jurnal Ilmu Fisika Indonesia Vol. 1, No (D): 82-83.

Harlianto, B. 2013. Pemetaan Percepatan Getaran Tanah Maksimum, Indeks Kerentanan Seismik Tanah, Ground Shear Strain, dan Ketebalan Lapisan Sedimen Untuk Mitigasi Bencana Gempa bumi di Kabupaten Bengkulu Utara. [Tesis]. Yogyakarta: Universitas Gadjah Mada.

Huang $\mathrm{H}$ and $\mathrm{Y}$. Tsen. 2002. Characteristics of soil liquefaction using $\mathrm{H} / \mathrm{V}$ of microtremor in Yuan-Lin area, Taiwan. TAO, Vol. 13, No. 3, 325-338.

Isihara, K.. 1982. Evaluation of soil properteis for use in Earthquake Response Analysis. Proc. Int. Symp. On Numerical Model in Geomech, 237-259.

Lubis, A. M., Hashima, A. and Sato, T., 2012. Analysis of afterslip distribution following the 2007 September 12 southern Sumatra earthquake using poroelastic and viscoelastic media, Geophys. J. Int. doi: 10.1093/gji/ggs020.

Nakamura, Y. 2000. Clear Identification of Fundamental Idea of Nakamura's Technique and Its Application. Proc XII World Conf. Earthquake Engineering. New Zealand, 2526.

Waluyo. 2002. Diktat Kuliah Seismologi. Yogyakarta: Program Studi Geofisika. UGM. 